14.2

\title{
Формирование гидрогелевых частиц из полиакриламида и PEGDA в микрофлюидном генераторе эмульсий с фокусировкой потока
}

\author{
(C) Д.В. Ноздрюхин, ${ }^{1,2}$ Н.А. Филатов, ${ }^{1}$ А.А. Евстрапов, ${ }^{1,3,4}$ А.С. Букатин ${ }^{1,4}$ \\ ${ }^{1}$ Санкт-Петербургский национальный исследовательский Академический университет РАН, \\ 194021 Санкт-Петербург, Россия \\ ${ }^{2}$ Санкт-Петербургский политехнический университет Петра Великого, \\ 195251 Санкт-Петербург, Россия \\ ${ }^{3}$ Университет ИТМО, \\ 197101 Санкт-Петербург, Россия \\ ${ }^{4}$ Институт аналитического приборостроения РАН, \\ 198095 Санкт-Петербург, Россия \\ e-mail: DaniN1909@yandex.ru
}

(Поступило в Редакцию 15 января 2018 г.)

Монодисперсные полимерные микрочастицы имеют большой потенциал для биомедицинских и физических применений. Современные высокопроизводительные технологии „капельной“ микрофлюидики позволяют формировать монодисперсные макроэмульсии „вода в масле“ с заданными параметрами. Проведение в макроэмульсии реакции полимеризации позволяет ее трансформировать в суспензию микрочастиц. Эти частицы могут рассматриваться как контейнеры для целевой доставки лекарственных средств, а также в качестве „биочернил“ для $3 D$-печати тканей и органов. Проведено исследование режимов формирования микрочастиц из PEGDA и полиакриламида в микрофлюидном генераторе макроэмульсий с фокусировкой потока. Для характеризации микрочастиц были измерены их геометрические размеры и механические свойства. Кроме того, была исследована динамика диффузионного выхода из микрочастиц малых молекул на примере флуоресцентного красителя Rhodamine B.

DOI: $10.21883 / J T F .2018 .09 .46423 .21-18$

\section{Введение}

В настоящее время монодисперсные полимерные микрочастицы находят широкое применение в биологических и медицинских исследованиях. Они рассматриваются в качестве перспективных кандидатов для создания таргетных средств доставки лекарственных препаратов $[1,2]$, кодирования фрагментов ДНК при секвенировании генома отдельных клеток [3], специфических маркеров для обнаружения и выделения онкомаркеров $[4,5]$, микрореакторов для проведения генетических исследований методом цифровой капельной полимеразной цепной реакции (ПЦР) [6], упаковки отдельных клеток для регенерации поврежденных тканей [7].

Одним из способов формирования монодисперсных микрочастиц является использование методов „капельной микрофлюидики“ (droplet microfluidic), которые позволяют формировать монодисперсную макроэмульсию (капли) „воды в масле“ за счет возникновения неустойчивости в области контакта двух несмешивающихся жидкостей. Получающуюся таким способом эмульсию широко используют в качестве капель-микрореакторов для проведения разнообразных биохимических реакций. В связи с возможностью формировать капли-микрореакторы с частотой до нескольких $\mathrm{kHz}$, этот подход находит широкое применение при скрининге перспективных лекарственных препаратов [8], проведении генетических исследований методом цифровой капельной ПЦР [9], а также синтезе полимерных микрочастиц [10]. Также в настоящее время изучается потенциал „капельной микрофлюидики“ для изготовления новых „умных“ материалов [11], оптических систем [12] и идентификационных меток [13].

Актуальным применением полимерных гидрогелевых микрочастиц является их использование для создания „биочернил“, позволяющих осуществлять $3 D$-печать тканей и органов [14]. Микрочастицы из биоразлагаемых материалов, например алгината натрия, применяются для упаковки клеток, а микрочастицы из биологически инертных материалов, таких как PEGDA и полиакриламид, - для создания поддерживающих структур (скаффолдов) [15]. Кроме того, в эти полимеры могут быть упакованы биологически активные молекулы или лекарственные средства, выделение которых в заданном пространстве позволит управлять формированием и развитием ткани или оказывать необходимое воздействие на участок организма.

Поэтому целью настоящей работы являлось определение условий и режимов воспроизводимого формирования монодисперсных гидрогелевых частиц из полиакриламида и полиэтиленгликоль диакрилата (Poly (ethylene glycol) diacrylate - PEGDA) в микрофлюидном генераторе эмульсий с фокусировкой потока. При этом важными задачами исследования были: а) оценка модуля упругости полимеризованных частиц; б) изучение кинетики выхода низкомолекулярных компонентов (на примере диффузии молекул флуорофоров) из гидрогелевых частиц. 


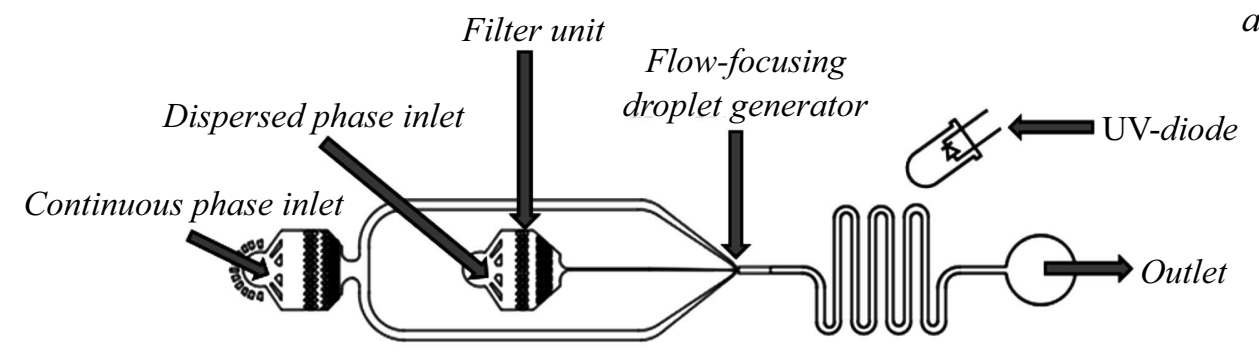

$a$
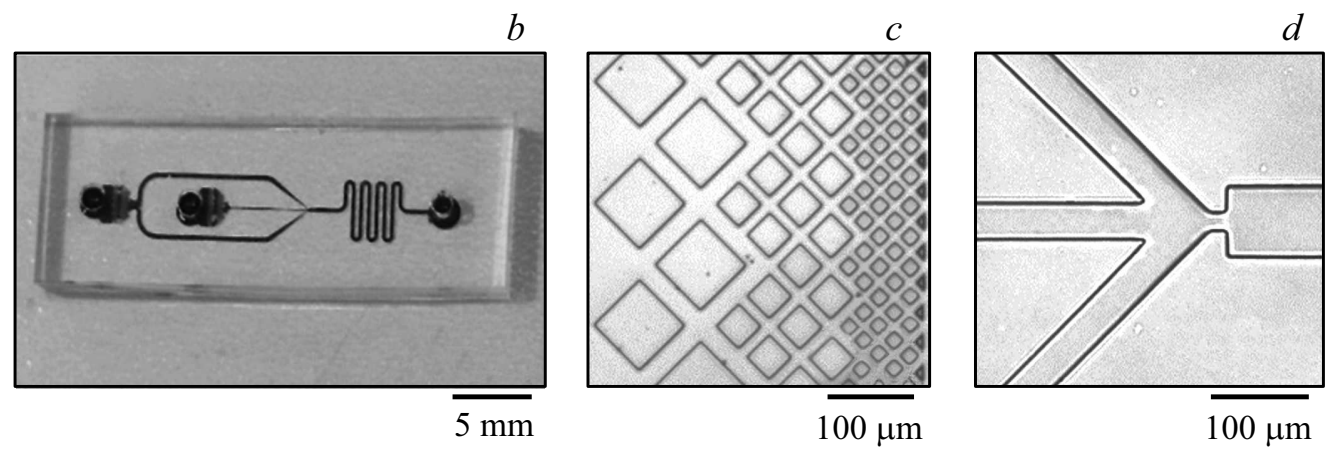

Рис. 1. $a-$ принципиальная схема микрофлюидного чипа для формирования монодисперсных гидрогелевых микрочастиц; $b-$ изображение микрофлюидного чипа, $c$ - изображение фильтра вблизи водного отверстия микрочипа; $d-$ изображение области формирования макроэмульсий.

\section{Микрофлюидные чипы с фокусировкой потока}

Для формирования монодисперсных макроэмульсий „вода в масле“ существует несколько типов топологий микрофлюидных генераторов, обеспечивающих соосное течение потоков, фокусировку потоков или Т-инжекцию [16]. Одними из основных параметров, определяющими условия формирования эмульсии, являются капиллярные числа непрерывной и дисперсной фаз. В микрофлюидном чипе с фокусировкой потока в зависимости от соотношения между капиллярными числами формирование эмульсии может происходить в капающем или струйном режиме [17]. Преимуществом использования топологии фокусировки потока являются более широкие возможности управления режимом генерации капель. Кроме того, за счет введения в конструкцию генератора капель, ограничивающей поток апертуры, обеспечивается возможность контроля размеров формируемой эмульсии независимо от частоты ее генерации.

Принципиальная схема использованных в работе микрофлюидных чипов с генератором капель и изображения чипа и его элементов представлены на рис. 1. Микрофлюидный чип содержит по одному входу для непрерывной и дисперсной фаз и один выход для сбора макроэмульсии или микрочастиц. Вблизи входных отверстий сформированы фильтрующие элементы, не допускающие попадания микрочастиц пыли и грязи в рабочие каналы чипа. Область формирования эмульсии представляет собой место соединения двух каналов для непрерывной фазы и одного центрального канала для дисперсной фазы, отделенного от выходного канала апертурой шириной $15 \mu \mathrm{m}$. Ширина выходного канала составляет $60 \mu \mathrm{m}$ вблизи апертуры и увеличивается до $120 \mu \mathrm{m}$. Глубина всех подводящих микроканалов и области формирования капель составляет $40 \mu \mathrm{m}$, глубина выходного канала вблизи апертуры также составляет $40 \mu \mathrm{m}$ и затем увеличивается до $120 \mu \mathrm{m}$ для предотвращения засорения выходного канала полимеризовавшимися микрочастицами.

Изготовление микрофлюидных чипов для проведения экспериментальных исследований осуществлялось с помощью технологии „мягкой“ литографии [18]. Полученные реплики в полидиметилсилоксане (ПДМС) Sylgard 184 (Dow Corning) затем были соединены со стеклами $25 \times 50 \mathrm{~mm}$ и толщиной $\sim 0.17 \mathrm{~mm}$ после обработки их поверхностей в кислородной плазме на установке Plasma Finish. Для придания внутренним поверхностям микроканалов гидрофобных свойств они были обработаны гидрофобизирующим агентом ClearVue Rain Repellent (Turtle Wax Inc.).

\section{Материалы и методы формирования гидрогелевых частиц в микрофлюидном генераторе макроэмульсий}

Для формирования монодисперсных макроэмульсий и гидрогелевых микрочастиц в качестве непрерывной фазы использовалось минеральное масло (каталожный № 330779, Sigma-Aldrich) с добавлением неионного поверхностно-активного вещества (ПАВ) ABIL EM 180 (Evonik Industries). ПАВ стабилизировал эмульсию и 


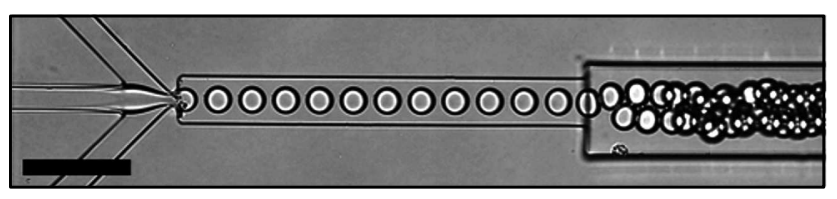

$b$

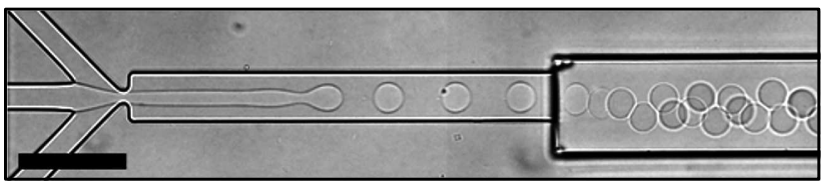

$c$

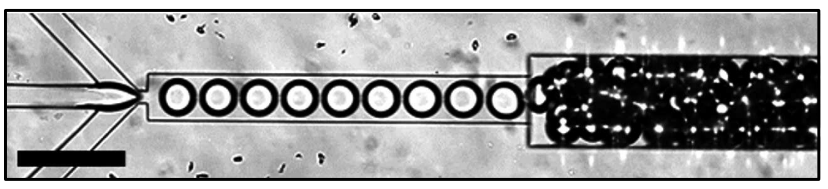

$d$

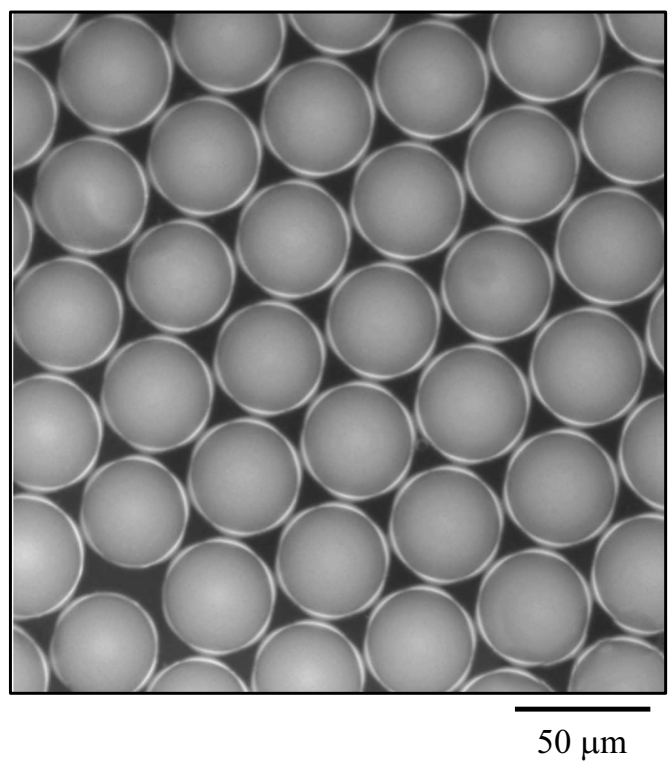

Рис. 2. $a$ - формирование 50\% PEGDA макроэмульсии в капающем режиме, $b$ - формирование $100 \%$ PEGDA макроэмульсии в струйном режиме, $c$ - формирование $10 \%$ полиакриламидной макроэмульсии в капающем режиме. Размерная метка соответствует $100 \mu \mathrm{m} ; d$ - изображение полиакриламидных микрочастиц с флуоресцентным красителем.

предотвращал ее коалесценцию за счет снижения поверхностного натяжения и создания потенциального барьера на границе двух фаз.

В качестве дисперсной фазы для формирования гидрогелевых частиц из PEGDA использовался водный раствор полиэтиленгликоль диакрилата (PEGDA) со средней молекулярной массой $700 \mathrm{Da}$ (каталожный № 455008 Sigma-Aldrich) в концентрации 0-100\% с добавлением фотоинициатора Irgacure 2959 (каталожный № 410896 Sigma-Aldrich) с концентрацией $1 \%$. При формировании полиакриламидных гидрогелевых микрочастиц в качестве дисперсной фазы использовался водный раствор акриламида/бис-акриламида (Bio-Rad) в концентрации 5-30\% с добавлением инициатора полимеризации пероксодисульфата аммония (Bio-Rad) в концентрации $0.3 \%$. В непрерывную среду добавлялся катализатор полимеризации TEMED в концентрации $1 \%$. Для исследования кинетики выхода веществ из микрочастиц в дисперсную фазу добавлялся флуоресцентный краситель Rhodamine B (каталожный № 83689 Sigma-Aldrich) в концентрации $0.1 \mathrm{mg} / \mathrm{ml}$.

Ввод жидкостей в микрофлюидный чип осуществлялся при постоянном давлении в диапазоне $5-50 \mathrm{kPa}$ с помощью четырехканального контроллера давлений, основанного на электропневматических интерфейсах ITV0001 (SMC, Japan). Наблюдение и регистрация процесса формирования макроэмульсии осуществлялись с помощью оптического микроскопа DM4000 (Leica, Германия) и CCD-камеры Pike 100B (AVT, Германия), обеспечивающей съемку с частотой до $200 \mathrm{fps}$. Для получения изображений во флуоресцентном режиме использовалась камера DFC 345 FX (Leica). Полимеризация
PEGDA микрочастиц в микрофлюидном чипе проводилась под воздействием УФ излучения лампы оптического микроскопа, сфокусированного объективом $10 \times$. Плотность мощности излучения на длине волны $365 \mathrm{~nm}$ составляла $\sim 80 \mathrm{~mW} / \mathrm{cm}^{2}$. Исследование механических характеристик микрочастиц осуществлялось с помощью атомно-силового микроскопа Bioscope Catalyst (Bruker) путем измерения силовых кривых подвода/отвода в контактном режиме.

\section{Результаты и обсуждение}

Формирование гидрогелевых микрочастиц с помощью микрофлюидных генераторов эмульсий осуществлялось в два этапа: на первом этапе формировалась монодисперсная макроэмульсия, в которой на втором этапе проводилась реакция полимеризации, в результате чего происходило преобразование макроэмульсии в суспензию микрочастиц. За счет использования апертуры шириной $15 \mu \mathrm{m}$ диапазон размеров макроэмульсии составил 15-80 $\mu \mathrm{m}$ независимо от состава дисперсной фазы.

Время полимеризации PEGDA-микрочастиц экспоненциально зависит от концентрации фотоинициатора и составляет $\sim 30 \mathrm{~s}$ при концентрации $1 \%$ [19]. Поэтому топология микрофлюидного чипа и скорость течения эмульсии были подобраны таким образом, чтобы реакция полимеризации PEGDA происходила в процессе ее движения по выходному каналу. Полимеризация полиакриламида начинается сразу после формирования эмульсии за счет диффузии катализатора TEMED из непрерывной фазы в дисперсную. В связи с тем, что концентрация TEMED в непрерывной фазе была 1\%, 

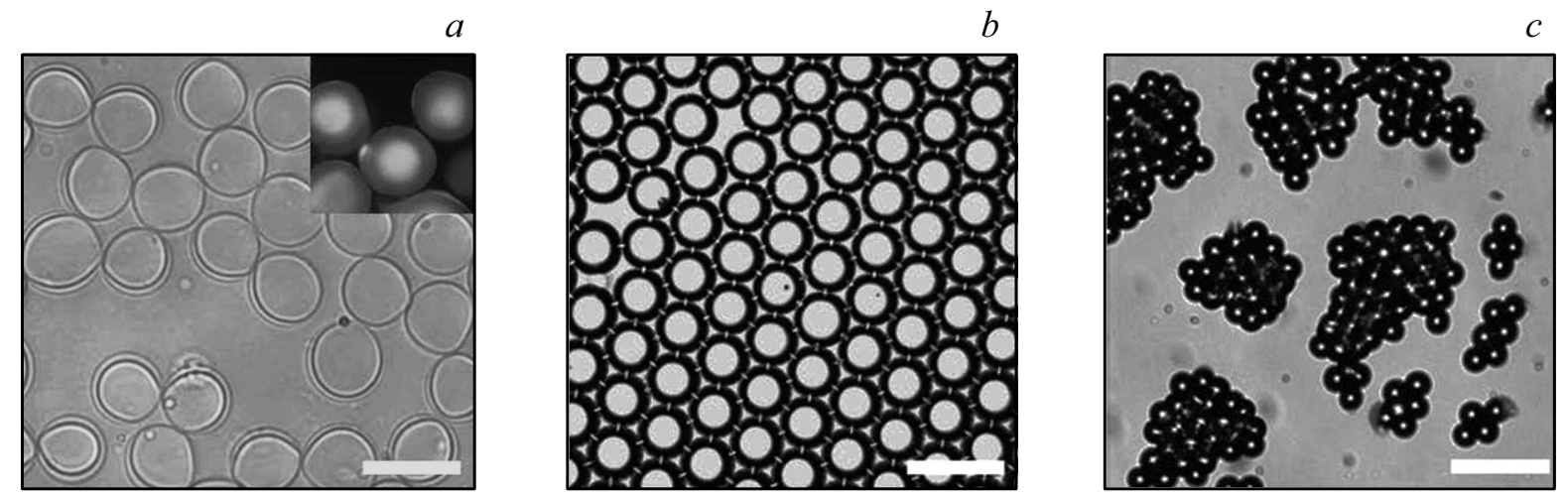

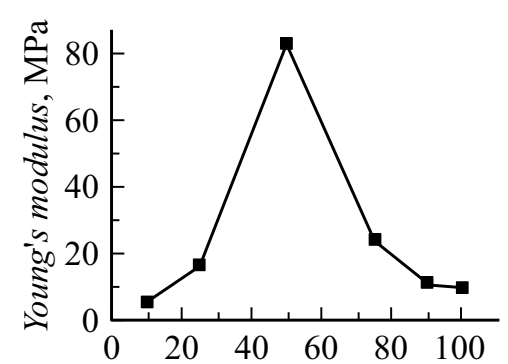

PEGDA content in solution, \%

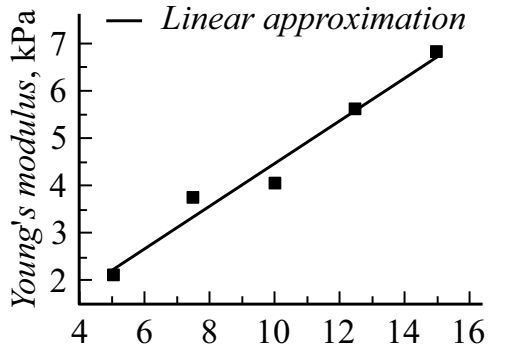

Acrylamide content in solution, $\%$

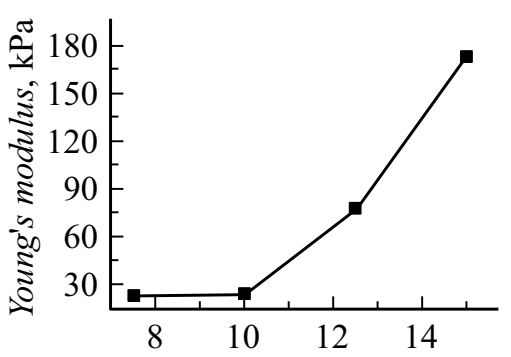

Acrylamide content in solution, \%

Рис. 3. Изображение и модуль Юнга гидрогелевых микрочастиц из: $a-100 \%$ PEGDA в жидкости, на вставке изображение микрочастиц с Rhodamine B во флуоресцентном режиме; $b-10 \%$ полиакриламида в жидкости, $c-10 \%$ полиакриламида в высушенном состоянии. Каждое значение модуля Юнга получено путем усреднения по трем измерениям.

время реакции составляло менее 1 min и на выходе из чипа микрочастицы были уже полностью полимеризованными.

Вязкость водного раствора неполимеризованного полиэтиленгликоля (PEG) зависит от его концентрации в широких пределах [20]. Поэтому при увеличении концентрации PEGDA в дисперсной фазе наблюдается изменение режима генерации эмульсии с капающего на струйный при формировании капель одинакового диаметра (рис. $2, a, b)$, что связано с увеличением капиллярного числа дисперсной фазы [17]. Вязкость неполимеризованного полиакриламида близка к вязкости воды и не зависит от его концентрации, поэтому формирование полиакриламидной эмульсии осуществлялось только в капающем режиме (рис. 2,c). При этом разброс размеров микрочастиц, сформированных в капающем режиме не превышает 5\%, в то время как в струйном режиме разброс размеров зависит от диаметра микрочастиц и может доходить до $30 \%$ в случае формирования частиц диаметром 15-20 $\mathrm{m}$. Пример сформированной полиакриламидной макроэмульсии представлен на рис. $2, d$.

Одной из основных характеристик полимерных микрочастиц является модуль упругости. С помощью метода атомно-силовой микроскопии был определен модуль Юнга микрочастиц в зависимости от концентрации PEGDA в диапазоне $10-100 \%$, который составил от 5 до $80 \mathrm{MPa}$ (рис. 3,a). Также было обнаружено, что при концентрации PEGDA выше 50\% у микрочастиц образуется мягкая оболочка с модулем Юнга от 0.5 до $2 \mathrm{MPa} \mathrm{[19].}$

Модуль упругости полиакриламидных частиц также зависит от концентрации полимера и составляет от 2 до $7 \mathrm{kPa}$ в водной среде. При помещении частиц в воздушную среду и выдерживании в течение $1 \mathrm{~h}$ при комнатной температуре происходит уменьшение их диаметра примерно в 2 раза и увеличение модуля упругости до 25-180 kРа в зависимости от концентрации полимера вследствие процесса дегидратации (рис. $3, b, c)$. После помещения обезвоженных микрочастиц в водную среду происходит восстановление их размеров до первоначальных значений.

C помощью флуоресцентного красителя Rhodamine B была исследована кинетика выхода малых молекул из микрочастиц диаметром $\sim 50 \mu \mathrm{m}$ (рис. 4) в воду. В частицах обоих типов интенсивность флуоресценции Rhodamine B экспоненциально спадает со временем. В случае $10 \%$ полиакриламида характерное время выхода красителя составило $4.2 \mathrm{~h}$, а в случае PEGDA характерное время зависит от концентрации полимера и составляет от 0.3 до $1.3 \mathrm{~h}$. Наибольшее время выхода красителя из микрочастиц с 25\% содержанием PEGDA, а наименьшее с 50\% содержанием PEGDA. Кроме того, остаточная интенсивность флуоресценции частиц составляет более $40 \%$, что говорит о низкой пористости материала. Также у некоторых микрочастиц была обнаружена неоднородность интенсивности флуо- 

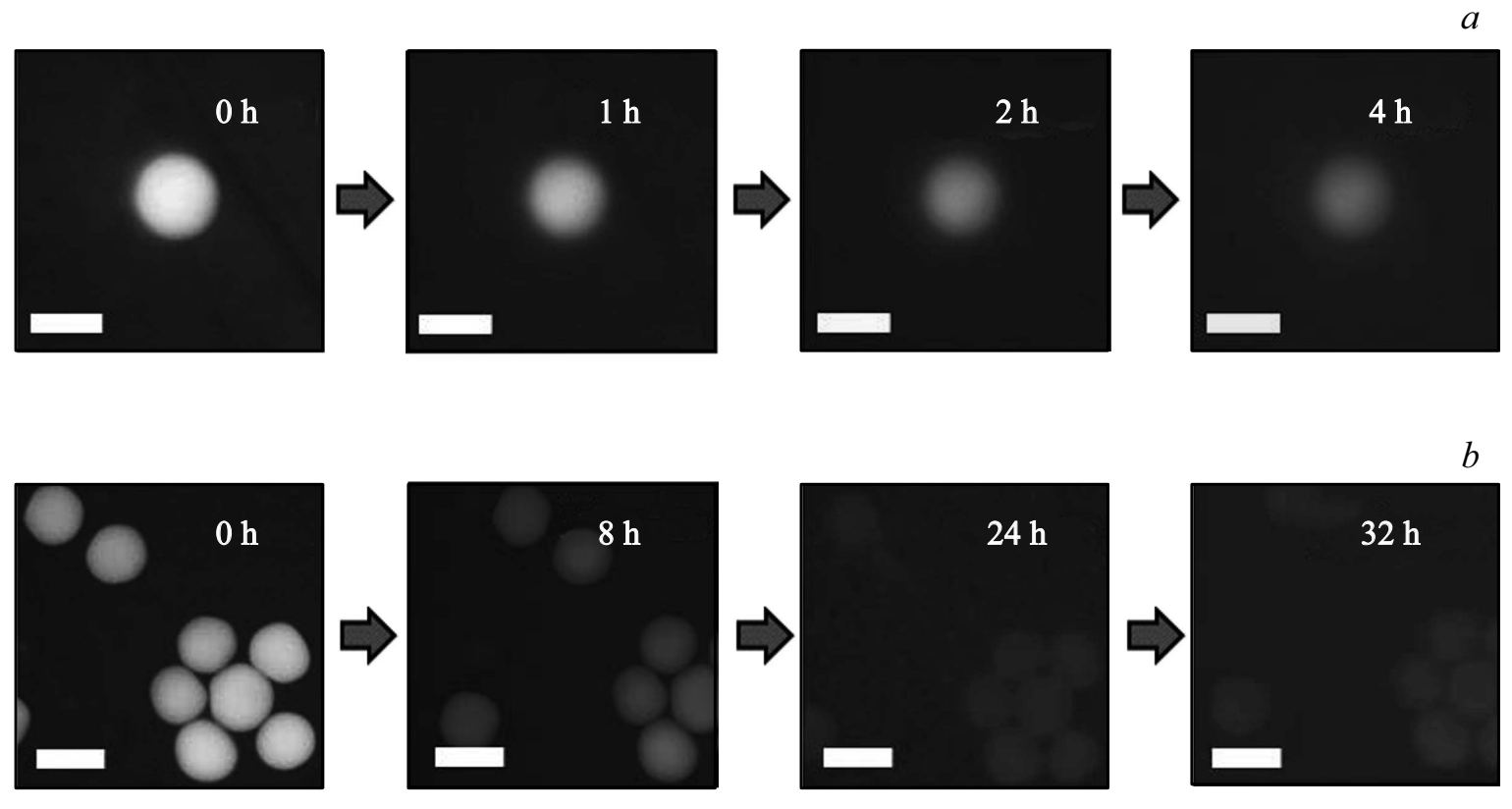

$c$

$d$
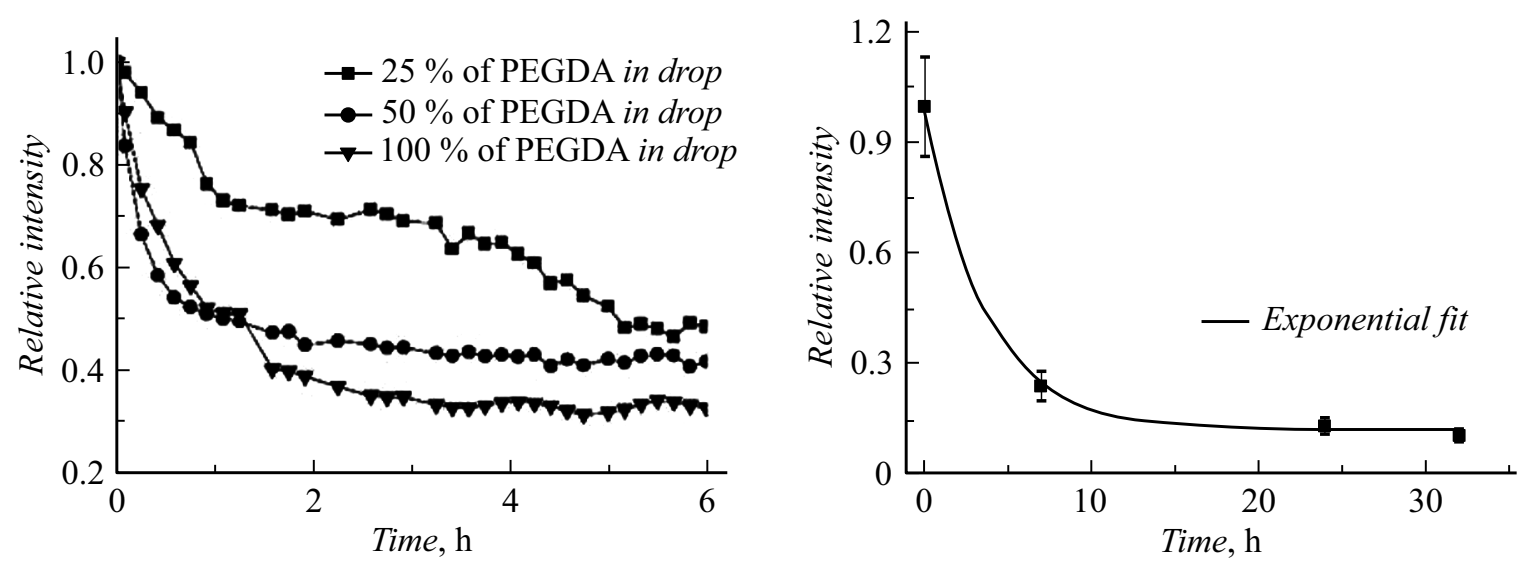

Pис. 4. Динамика изменения интенсивности флуоресценции Rhodamine В в микрочастицах: $a-50 \%$ PEGDA; $b-$ $10 \%$ полиакриламида; $c$ - зависимость интенсивности флуоресценции микрочастиц с разной концентрацией PEGDA, $d-$ зависимость интенсивности флуоресценции в микрочастицах с 10\% полиакриламида. Каждая точка графиков получена при усреднении интенсивности флуоресценции 5 микрочастиц. Размерная метка соответствует $50 \mu \mathrm{m}$.

ресценции, что может объясняться разной плотностью материала и зависимостью концентрации PEGDA от центра частицы (рис. 3,a). Это может быть связано с тем, что полимеризация частицы начинается с ее центра, и за время полимеризации может произойти обеднение области вблизи границы.

\section{Заключение}

В настоящей работе исследованы режимы формирования монодисперсных микрочастиц из PEGDA и полиакриламида в микрофлюидном генераторе макроэмульсий. Режим генерации определяется вязкостью дисперсперсной фазы и при увеличении концентрации PEGDA изменяется с капающего на струйный, ухудшая при этом показатель монодисперсности частиц с 5 до 30\%.

Исследование модуля Юнга микрочастиц показало, что их упругими свойствами можно управлять путем изменения концентрации полимера. При этом модуль Юнга PEGDA-частиц в водной среде находится в диапазоне 5-80 МРа, а полиакриламидных частиц - 2-7 kPa, что, вероятно, связано с высокой пористостью полиакриламида в отличие от PEGDA. Это же свойство проявляется при диффузионном выходе малых молекул, упакованных в микрочастицы, в водную среду. Изучение этого эффекта с помощью флуоресцентного красителя Rhodamine B показало, что у PEGDA-микрочастиц высокая интенсивность остаточной флуоресценции, а характерное время диффузионного выхода составляет 
от 0.3 до $1.3 \mathrm{~h}$. В случае полиакриламидных микрочастиц характерное время составляет $4.2 \mathrm{~h}$. Таким образом, PEGDA-микрочастицы могут быть использованы для формирования $3 D$-каркаса в процессе биопечати, a полиакриламидные частицы для управляемого ввода в растущую культуру биологически активных веществ непосредственно сразу после печати, а также для целевой доставки лекарственных средств в заданную область организма.

Работа выполнена при поддержке гранта Президента Российской Федерации МК-2131.2017.4.

\section{Список литературы}

[1] Choi A., Seo K.D., Kim D.W., Kim B.C., Kim D.S. // Lab. Chip. 2017. Vol. 17. P. 591-613. DOI: 10.1039/C6LC01023G

[2] Mazutis L., Vasiliauskas R., Weitz D.A. // Macromol. Biosci. 2015. 15. P. 1641-1646. DOI: 10.1002/mabi.201570046

[3] Zilionis R., Nainys J., Veres A., Savova V., Zemmour D., Klein A.M., Mazutis L. // Nat. Protoc. 2017. Vol. 12. P. 4473. DOI: $10.1038 /$ nprot.2016.154

[4] Hwang H., Kim S.-H., Yang S.-M. // Lab. Chip. 2011. Vol. 11. P. 87-92. DOI: $10.1039 /$ C0LC00125B

[5] Gao R.K., Cheng Z.Y., Demello A.J., Choo J. // Lab. Chip. 2016. Vol. 16. P. 1022-1029. DOI: 10.1039/C5LC01249J

[6] Zhu Z., Zhang W., Leng X., Zhang M., Guan Z., Lu J., Yang C.J. // Lab. Chip. 2012. Vol. 12. P. 3907-3913.

DOI: $10.1039 / \mathrm{C} 2 \mathrm{LC} 40461 \mathrm{C}$

[7] Jiang W., Li M., Chen Z., Leong K.W. // Lab. Chip. 2016. Vol. 16. P. 4482-4506. DOI: 10.1039/c6lc01193d

[8] Shembekar N., Chaipan C., Utharalaa R., Merten C.A. // Lab. Chip. 2016. Vol. 16. P. 1314-1331.

DOI: $10.1039 / \mathrm{C} 6 \mathrm{LC} 00249 \mathrm{H}$

[9] Huggett J.F., Cowen S., Foy C.A. // Clin Chem. 2015. Vol. 61. N 1. P. 79-88. DOI: 10.1373 /clinchem.2014.221366

[10] Kim J.H., Jeon T.Y., Choi T.M., Shim T.S., Kim S.-H., Yang S.M. // Langmuir, 2014, 30 (6), P. 1473-1488. DOI: $10.1021 / \mathrm{la} 403220 \mathrm{p}$

[11] Liu S.-S., Wang C.-F., Wang X.-Q., Zhang J., Tian Y., Yin S.N., Chen S. // J. Mater. Chem. C. 2014. N 2. P. 9431-9438. DOI: $10.1039 / \mathrm{C} 4 \mathrm{TC} 01631 \mathrm{~A}$

[12] Nisisako T., Suzuki H., Hatsuzawa T.// Micromachines. 2015. Vol. 6. P. 1435-1444. DOI: 10.3390/mi6101428

[13] Geng Y., Noh J., Drevensek-Olenik I., Rupp R., Lenzini G., Lagerwall J.P.F. // Scientific Reports. 2016. Vol. 6. DOI: $10.1038 /$ srep26840

[14] Vadivelu R.K., Kamble H., Shiddiky M.J.A., Nguyen N.-T. // Micromachines 2017. Vol. 8. P. 94. DOI: 10.3390/mi8040094

[15] DeForest C.A., Polizzotti B.D., Anseth K.S. // Nat. Mater. 2009. Vol. 8. P. 659-664. DOI: $10.1038 /$ nmat 2473.

[16] Кухтевич И.В., Посмитная Я.С., Белоусов К.И., Букатин А.С., Евстрапов А.А. // Научное приборостроение. 2015. Т. 25. Вып. 3. С. 65-85.

[17] Cubaud T., Mason T.G. // Phys. Fluid. 2008. Vol. 20. P. 053302. DOI: $10.1063 / 1.2911716$

[18] Букатин А.С., Мухин И.С., Малышев Е.И., Кухтевич И.В., Евстрапов А.А., Дубина М.В. // ЖТФ. 2016. Т. 61. Вып. 10. C. 1566-1571. [Bukatin A.S., Mukhin I.S., Malyshev E.I., Kukhtevich I.V., Evstrapov A.A., Dubina M.V. // Tech. Phys. 2016. Vol. 61. N 10. P. 1566-1571.]
[19] Filatov N.A., Nozdriukhin D.V., Bukatin A.S. // J. Phys.: Conf. Ser. 2017. Vol. 917. P. 042024. DOI: $10.1088 / 1742-6596 / 917 / 4 / 042024$

[20] Gonzalez-Tello P., Camacho F., Blazquez G. // J. Chem. Eng. Data. 1994. Vol. 39. N 3. P. 611-614. DOI: $10.1021 / \mathrm{je} 00015 \mathrm{a} 050$ 